E3S Web of Conferences 1, 33006 (2013)

DOI: $10.1051 / \mathrm{e} 3 \operatorname{sconf} / 20130133006$

C) Owned by the authors, published by EDP Sciences, 2013

\title{
Mobility and Bioavailability of Metals in sediments of Skadar Lake - Montenegro
}

\author{
V. R. Kastratović ${ }^{1}$, D. D. Đurović ${ }^{2}$, S. D. Krivokapić ${ }^{1}$ and B. P. Mugoša ${ }^{2}$ \\ ${ }^{1}$ University of Montenegro, Faculty of Science, Department of Biology, G.Washington Street P. fax 5455, \\ 81000Podgorica, MONTENEGRO,vlatkok@ac.me \\ ${ }^{2}$ Institute of Public Health of Montenegro, Ljubljanska bb, 81000 Podgorica, MONTENEGRO, soilchen@ntu.edu.tw, \\ dil@t-com.me
}

\begin{abstract}
Metals in sediments are present in different chemical forms, which mostly affect their ability to transfer in water and plants i.e. their bioavailability. The mobile part of metals is potentially toxic, thus for the evaluation of the bioavailability it is often enough to determine the metal content in the available and potentially available fraction of sediment. The aim of this study was to compare some methods of determination of mobile forms of heavy metals and to determine their share related to the "pseudo-total" metal content in the sediment from Skadar Lake, Montenegro. Mobile forms of $\mathrm{Cu}, \mathrm{Co}, \mathrm{Cr}, \mathrm{Mn}, \mathrm{Ni}, \mathrm{Pb}, \mathrm{Zn}, \mathrm{Sr}$ and $\mathrm{V}$ were determined using: $0.1 \mathrm{M} \mathrm{NH}_{4} \mathrm{Cl}$ (buffered to $\mathrm{pH}$ 9), $0.1 \mathrm{M} \mathrm{CaCl}_{2}\left(\mathrm{pH}\right.$ 6), 0.1 $\mathrm{M} \mathrm{CH}_{3} \mathrm{COONa}(\mathrm{pH} 9), 0.1 \mathrm{M}$ $\mathrm{H}_{2} \mathrm{C}_{2} \mathrm{O}_{4}(\mathrm{pH}$ 2) and 0.1M EDTA (pH 6), The largest amounts of $\mathrm{Co}(42.2 \mathrm{wt} . \%), \mathrm{Cr}(11.4 \%), \mathrm{Mn}(59.9 \%)$, Ni (13.5\%), Zn (41.0\%) and V (42.2\%) were extracted with oxalic acid and $\mathrm{Cu}(44.7 \mathrm{wt} . \%), \mathrm{Pb}(49.3 \%)$, and $\mathrm{Sr}$ (61.2\%) with EDTA. With $\mathrm{NH}_{4} \mathrm{Cl}, \mathrm{CaCl}_{2}$ and $\mathrm{CH}_{3} \mathrm{COONa}$ small amounts of metals were extracted (except $\mathrm{Sr}$ ), generally below $1 \%$. Based on these results we can conclude that the metals in the sediments of Lake Skadar are found in a negligible amount in easily mobile, acid soluble and carbonate-related phase.
\end{abstract}

Key words: bioavailability, chemical forms, heavy metals, sediment, Skadar Lake

\section{Introduction}

The sediments are integral parts of the aquatic environment and the main carriers of all types of pollutants. One of the most important group of pollutants from the ecotoxicological aspect are heavy metals. Metals in sediments are found in different physical and chemical forms that determine their behavior in the aquatic environment (Gleyzes et al., 2002). Those in the sediment go through the various processes and pathways that include their association, precipitation, adsorption, chelatisation etc. (Chakravarty and Patgiri, 2009). The data on total or "pseudo"-total content does not provide a clear image of their mode of binding to sediment. Of much greater importance is the information about mobility, bioavailability and toxicity of metals from sediments (Gao et al., 2010). Metals in sediments can be found in six fractions, and depending on the phase they are connected to, they show different levels of mobility (Mossop and Davidson, 2003; Hlavay et al., 2004). Changing environmental conditions such as $\mathrm{T}, \mathrm{pH}$, redox potential, concentration of organic ligands and similar can lead to the release of metals in solid or liquid phase and cause contamination of the surrounding aquatic system (Sahuaquillo et al., 2003).

In practice, environmental studies involving sediments are often based on the use of extraction procedures (eg. single or sequential), which include broader forms or phases of metals (eg. bioavailable forms, chelated etc.) and which are in most cases sufficient for the purpose of environmental considerations (Quevanviller, 1998).

In our study, the metals: $\mathrm{Cu}, \mathrm{Co}, \mathrm{Cr}, \mathrm{Mn}, \mathrm{Ni}, \mathrm{Pb}, \mathrm{Zn}$, $\mathrm{V}$ and $\mathrm{Sr}$ are extracted from the sediments of Lake Skadar, Montenegro, with five different extracting solutions: cation-exchangeable $\left(\mathrm{NH}_{4} \mathrm{Cl}, \mathrm{CaCl}_{2}\right.$, $\mathrm{CH}_{3} \mathrm{COONa}$ ), organic acid (oxalic acid) and complexing reagent (EDTA). These solutions represent real environmental conditions, so the aim of this study was to determine the proportion of mobile and mobilizable metals in sediments and predict their bioavailability.

\section{Materials and Methods}

Skadar Lake is the largest lake in the Balkans, with the surface of $391 \mathrm{~km}^{2}$. Montenegro owns 2/3 of Lake, while $1 / 3$ of the territory belongs to the Republic of 
Albania. The Montenegrin part of the lake with the surrounding area was declared a national park in 1983.

Sediment samples were collected from eight locations of Skadar Lake during June 2011. The tributaries and effluents of the lake, parts visited by tourists and fishermen, the middle of the lake and nature reserve were chosen as sampling sites.

The sediment sampling was done randomly from the surface of $10 \times 10 \mathrm{~m}$. Samples were taken by Ekman dredger from the depth of $0-20 \mathrm{~cm}$. From each sampling site three sub-samples were made. The samples were packed by plastic spatula in plastic boxes and transported to the laboratory. In laboratory samples were dried, crushed, grind and sieved to fractions $<1.5 \mathrm{~mm}$. During all the operations plastic equipment or stainless steel tools were used.

The total metal content was determined after the digestion in the liquid region (Kilburn, 2000).

The quantities of extracted heavy metals were determined in different chemical extractants. The amount of extraction element depends on the nature of extractant, sediment/extractant relation, $\mathrm{pH}$, extraction time and methodology. The used extractants and extraction conditions are shown in Table 1.

Table 1. Extractants used for sediment testing

\begin{tabular}{|l|c|c|c|}
\hline Extractant & $\mathrm{pH}$ & $\begin{array}{c}\text { Sed../extr. } \\
\text { ratio } \\
(\mathrm{g}: \mathrm{ml})\end{array}$ & $\begin{array}{c}\text { Extrac } \\
\text { time } \\
(\mathrm{h})\end{array}$ \\
\hline $0.1 \mathrm{M} \mathrm{NH} \mathrm{N}_{4} \mathrm{Cl}$ & 9.0 & $3: 50$ & 16 \\
(buffered) & & & \\
$0.1 \mathrm{M} \mathrm{CaCl}_{2}$ & 6.0 & $3: 50$ & 16 \\
$0.1 \mathrm{M} \mathrm{CH}_{3} \mathrm{COONa}_{2}$ & 9.0 & $3: 50$ & 16 \\
$0.1 \mathrm{M} \mathrm{H}_{2} \mathrm{C}_{2} \mathrm{O}_{4}$ & 2.0 & $1: 50$ & 1 \\
$0.1 \mathrm{M} \mathrm{EDTA}$ & 6.0 & $1: 50$ & 1 \\
\hline
\end{tabular}

The content of the studied heavy metals $(\mathrm{Cu}, \mathrm{Co}, \mathrm{Cr}, \mathrm{Mn}$, $\mathrm{Ni}, \mathrm{Pb}, \mathrm{Zn}, \mathrm{V}$ and $\mathrm{Sr}$ ) was determined by ICP-OES technique, the manufacturer Spectro Arcos. Among heavy metals $\mathrm{Cd}$ was also investigated, but it was not detected in the investigated sediment.

\section{Results and Discussion}

The total and extracted concentrations (range and mean values) of the investigated metals in the sediments of Lake Skadar are given in Table 2.

In Table 2 it can be seen that significantly smaller amounts of metals are extracted with $\mathrm{NH}_{4} \mathrm{Cl}, \mathrm{CaCl}_{2}$ and $\mathrm{CH}_{3} \mathrm{COONa}$ than with $\mathrm{H}_{2} \mathrm{C}_{2} \mathrm{O}_{4}$ (oxalic acid) and EDTA.

The release of metal ions linked by weak electrostatic forces is often performed by ammoniac salts ion exchange (Ure, 1996). Ammonium salts of strong acids such as ammonium chloride are used for the extraction of metals in easily soluble and exchangeable phases of sediments. The results show that very small amounts of heavy metals in sediment samples are tested in exchangeable fraction. Extractability, corresponding to the mobility follows the order $\mathrm{Mn}, \mathrm{Sr}>\mathrm{Ni}>\mathrm{V}>\mathrm{Co}, \mathrm{Cu}$, $\mathrm{Cr}, \mathrm{Pb}, \mathrm{Zn}$. Expressed in percentage relative to the total metal content in the sediment, all metals are extracted below $1 \%$, except for $\mathrm{Sr}(3.96 \%)$, which is the most mobile of the investigated metals. The amount of $\mathrm{Ni}$ extracted with $\mathrm{NH}_{4} \mathrm{Cl}$ shows a high correlation, while the content of $\mathrm{Mn}$ shows a very high correlation with the total content of metals in sediment samples. The quantities of other extracted metals are not correlated with the total content in the sediments.

$\mathrm{CaCl}_{2}$ solution has a similar ionic strength and $\mathrm{pH}$ as the sediment solution and it can extract metals that are mobile in natural conditions. These are generally fractions of metals weakly associated to colloidal particles of sediment. Compared to the extraction with $\mathrm{NH}_{4} \mathrm{Cl}$, higher extracted amounts of $\mathrm{Pb}(4.45 \%), \mathrm{Mn}$ $(4.61 \%)$ and $\mathrm{Sr}(8.68 \%)$ are noticed. The reason for this is lower $\mathrm{pH}$ in $\mathrm{CaCl}_{2}$ solution, the higher water solubility of their chlorides and their coprecipitation at higher $\mathrm{pH}$ values (buffered $\mathrm{NH}_{4} \mathrm{Cl}$ with $\mathrm{pH}$ 9). At higher $\mathrm{pH}$ value coprecipitation and incorporation of metals in the crystal hydroxides and carbonates lattices occur. The low concentration of $\mathrm{Cu}$ extracted by these extractants indicates that it is mainly present in the sediment in the form of organic complexes and in such situations, these reagents are not recommended for its extraction (Symeonides and McRae, 1977).

For the extraction of $\mathrm{Cu}$ the solution of $\mathrm{Na}$-acetate is more suitable, because of more complexing power of acetate ion and its ability to prevent deposition or readsorption of the released metal ions (Podlesakova et al., 2001). This reagent, other than $\mathrm{Cu}$ extracts also large amounts of $\mathrm{Zn}$ and $\mathrm{V}$ compared with $\mathrm{CaCl}_{2}$ and $\mathrm{NH}_{4} \mathrm{Cl}$. Compared to previous extractants smaller amount of $\mathrm{Co}$ (not detected), and Mn was extracted with Na-acetate. At the basic $\mathrm{pH}$ values, there is no release of carbonate bound metals, only soluble and easily exchangeable metal is extracted. The extracted amounts of all studied metals with $\mathrm{CaCl}_{2}$ and Na-acetate were not correlated with the total content in the sediment samples.

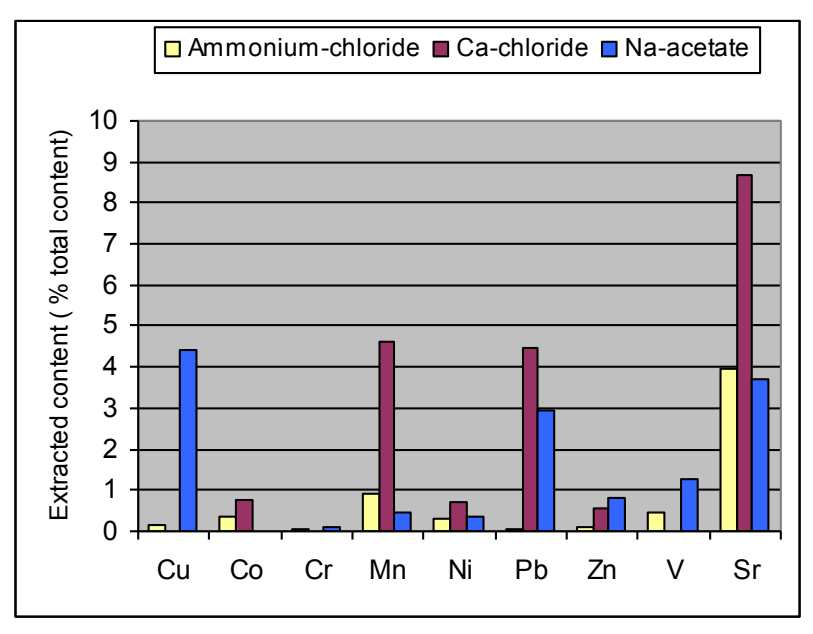

Fig. 1. Scale of mobility of metals obtained by simple extraction $\left(\mathrm{NH}_{4} \mathrm{Cl}, \mathrm{CaCl}_{2}\right.$ and $\left.\mathrm{CH}_{3} \mathrm{COONa}\right)$

Oxalic acid and EDTA extracted significantly greater amounts of metals than the previous three extractants. The $0.1 \mathrm{M}$ oxalic acid extracted heavy metals from 
Table 2. Minimum, maximum and mean values of total content and extracted metals $(\mathrm{mg} / \mathrm{kg})$ in sediments of Lake Skadar

\begin{tabular}{|l|c|c|c|c|c|c|c|}
\hline & & Total metals & $\mathrm{NH}_{4} \mathrm{Cl}$ & $\mathrm{CaCl}_{2}$ & $\mathrm{CH}_{3} \mathrm{COONa}$ & Oxalic acid & EDTA \\
\hline $\mathrm{Cu}$ & Min.-max. & $27.2-50.4$ & $0-0.32$ & $\mathrm{nd}$ & $0.59-2.72$ & $10.3-17.9$ & $11.6-19.2$ \\
& Mean & 35.8 & 0.05 & & 1.59 & 13.8 & 16.0 \\
\hline $\mathrm{Co}$ & Min.-max. & $6.31-13.0$ & $0.02-0.05$ & $0.02-0.30$ & $\mathrm{nd}$ & $1.78-6.34$ & $0.60-2.65$ \\
& Mean & 8.96 & 0.03 & 0.07 & & 3.78 & 1.46 \\
\hline $\mathrm{Cr}$ & Min.-max. & $42.4-127$ & $0-0.22$ & $\mathrm{nd}$ & $0-0.20$ & $3.08-16.4$ & $0.29-3.36$ \\
& Mean & 69.7 & 0.04 & & 0.08 & 7.92 & 1.20 \\
\hline $\mathrm{Mn}$ & Min.-max. & $99.0-424$ & $0.79-5.07$ & $4.16-20.6$ & $0.20-2.36$ & $39.7-292$ & $32.8-331$ \\
& Mean & 232 & 2.14 & 10.7 & 1.02 & 139 & 128 \\
\hline $\mathrm{Ni}$ & Min.-max. & $29.3-131$ & $0.15-0.34$ & $0.36-0.72$ & $0-0.74$ & $3.16-17.8$ & $1.09-9.93$ \\
& Mean & 79.0 & 0.22 & 0.56 & 0.26 & 10.7 & 4.32 \\
\hline $\mathrm{Pb}$ & Min.-max. & $19.1-43.2$ & $0-0.02$ & $1.18-1.52$ & $0-2.16$ & $0-0.86$ & $8.40-24.7$ \\
& Mean & 29.0 & 0.01 & 1.29 & 0.86 & 0.50 & 14.3 \\
\hline $\mathrm{Zn}$ & Min.-max. & $47.6-117$ & $0-0.24$ & $0-2.37$ & $0-1.89$ & $14.5-76.9$ & $6.00-52.5$ \\
& Mean & 75.4 & 0.07 & 0.41 & 0.63 & 30.9 & 18.0 \\
\hline $\mathrm{V}$ & Min.-max. & $20.4-46.7$ & $0-0.29$ & nd & $0.19-0.86$ & $6.28-27.1$ & $3.75-18.4$ \\
& Mean & 29.4 & 0.13 & & 0.37 & 12.4 & 7.51 \\
\hline $\mathrm{Sr}$ & Min.-max. & $17.7-101$ & $1.48-2.97$ & $2.54-8.77$ & $1.52-3.05$ & $2.37-6.66$ & $6.12-83.2$ \\
& Mean & 55.1 & 2.18 & 4.78 & 2.04 & 4.70 & 33.7 \\
\hline
\end{tabular}

sediments of several fractions: exchangeable, complex with organic matter and related to minerals (carbonates, oxides) and partly for iron and manganese hydroxides. This reagent extracts significant amounts of metals due to low $\mathrm{pH}(\mathrm{pH} 2)$ and possibility of metal complexation with oxalate ions. All the extracted amounts of metals show high or very high correlation with the total content of metals in sediments. EDTA forms stable complexes with many metals. It released exchangeabe heavy metals from sediments and organic complexed metals (KabataPendias and Pendias, 1984; Podlesakova et al., 2001). It also extracted the metals associated with carbonates and hydroxides of iron and manganese (Beckett, 1989).

The extraction potential of these two extractants was compared to predict their ability to influence the remobilisation and release of the weakly sediment-bound (mobile) and mobilisable (potentially mobile) metal ions.

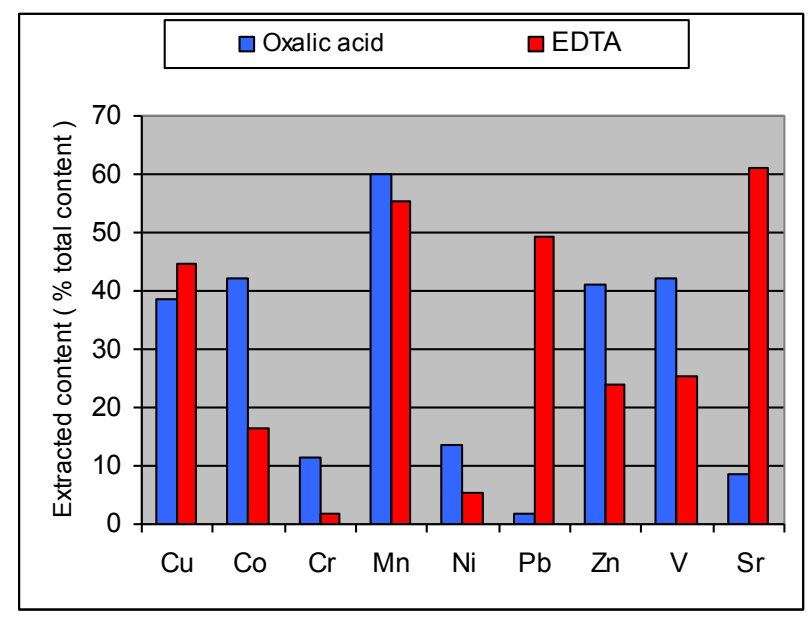

Fig. 2. Scale of mobility of metals obtained by simple extraction (oxalic acid and EDTA)
The acidic conditions $\left(0.1 \mathrm{M} \mathrm{H} \mathrm{H}_{2} \mathrm{C}_{2} \mathrm{O}_{4}, \mathrm{pH} 2\right)$ showed higher potential for the extraction of $\mathrm{Co}, \mathrm{Cr}, \mathrm{Mn}, \mathrm{Ni}, \mathrm{Zn}$ and $\mathrm{V}$, while complexing extraction conditions $(0.1 \mathrm{M}$ EDTA, $\mathrm{pH}$ 6) provide higher concentration of $\mathrm{Cu}, \mathrm{Pb}$ and Sr. The greatest differences between the extractions of these two solvents was reported in $\mathrm{Pb}, \mathrm{Sr}$ and $\mathrm{Cr}$.

$\mathrm{Pb}$ is 28.7 times and $\mathrm{Sr} 7.2$ times more extracted with EDTA than with oxalic acid. $\mathrm{Pb}$ and $\mathrm{Sr}$ showed great sensitivity to complexation, and $\mathrm{Pb}$ has the highest oxalate solubility product of the investigated metals. $\mathrm{Cr}$ showed a 6.6 times greater extrability in oxalic acid than in EDTA. The creation of $\mathrm{Cr}$ (III)-EDTA complex at room temperature is very slow, despite its high stability constant $(\mathrm{pK}=23)$.

\section{Conclusion}

The amounts of metals extracted with $\mathrm{NH}_{4} \mathrm{Cl}, \mathrm{CaCl}_{2}$ and $\mathrm{CH}_{3} \mathrm{COONa}$ show that only a small part of the studied metals in the sediments of Lake Skadar is found in labile, easily soluble form available to biota. In more extreme conditions $\left(0.1 \mathrm{M} \mathrm{H}_{2} \mathrm{C}_{2} \mathrm{O}_{4}\right.$ and $0.1 \mathrm{M}$ EDTA) about half of the total quantity of metals is released, either in one or in another solvent, except for $\mathrm{Cr}$ and $\mathrm{Ni}$. These metals are mostly incorporated in the crystal lattice of minerals. The highest mobility was shown by $\mathrm{Sr}$, which was isolated in the highest amount in the solutions $\mathrm{NH}_{4} \mathrm{Cl}, \mathrm{CaCl}_{2}$ and EDTA, with regard to the total content of the studied metals.

\section{References}

Beckett P. H. T. The use of extractants in studies on trace metals in soils, sewage sludges and sludge treated soils. Advances in Soil Science. 1989. Vol. 9. P. 143-176. 
Chakravarty M. and Patgiri A.D., Metal Pollution Assessment in Sediments of the Dikrong River, N.E. India, J Hum Ecol, 27(1), (2009) 63-67.

Gao et al., Environmental status of Daya Bay surface sediments inferred from a sequential extraction technique, Estaurine, Coastal and Shelf Science 86 (2010) 369-378.

Gleyzes, C. et al., Fractionation studies of trace elements in contaminated soils and sediments: a review of sequential extraction procedures. Trends in analytical chemistry 21 , (2002) 451-467.

Hlavay, J. et al., Determination of trace elements bound to soils and sediment fractions. Pure Appl. Chem. (2004) 76: 415-442.

Kabata-Pendias A., Pendias H. Trace Elements in Soils and Plants. CRC Press, Boca Raton, FL., 1984.

Kilburn M. Aqua Regia Digestion for Soils / Sludges. Analytical methods manual. Method NO: H115, (2000).

Mossop, K.F. and Davidson, C.M.,Comparison of original and modified BCR sequential extraction procedures for the fractionation of copper, iron, lead, manganese and zinc in soils and sediments. Analytical Chimica Acta 478, (2003) 111-118.

Podlesakova E. et al. Mobility and bioavailability of trace elements in soils. Trace Elements in Soil. Bioavailability,Flux, and Transfer. Edited by I. K. Iskandar and M. B. Kirkham. USA, 2001.

Quevauviller, $\mathrm{Ph}$, Operationally defined extraction procedures for soil and sediment analysis I. Standardization. Trends in Analytical Chemistry 17, (1998) 289.

Sahuquillo, A.et al. Overview of the use of leaching/extraction tests for risk assessment of trace metals in contaminated soils and sediments. Trends in Analytical Chemistry 22, (2003) 152-159.

Symeonides A., McRae S. S. The assessment of plantavailable cadmium in soils. J. Environ. Qual. 1977. Vol. 6. N 2. P. 120-122.

Ure A. M. Single extraction schemes for soil analysis and related applications. The Science of the Total Environment. (1996) Vol. 178. P. 3-10. 